Check for updates

Cite this: Chem. Sci., 2018, 9, 1155

Received 23rd November 2017 Accepted 4th December 2017

DOI: $10.1039 / \mathrm{c} 7 \mathrm{sc} 05034 \mathrm{~h}$

rsc.li/chemical-science

\title{
How to tame a palladium terminal oxo $\uparrow$
}

\author{
Dominik Munz (D) *
}

The isolation of terminal oxo complexes of the late transition metals promises new avenues in oxidation catalysis like the selective and catalytic hydroxylation of unreactive $\mathrm{CH}$ bonds, the activation of water, or the upgrading of olefins. While terminal oxo ligands are ubiquitous for early transition metals, wellcharacterized examples with group 10 metals remain hitherto elusive. In search for palladium terminal oxo complexes, the relative stability/reactivity of such compounds are evaluated computationally (CASSCF/NEVPT2; DFT). The calculations investigate only well-known ligand systems with established synthetic procedures and relevance for coordination chemistry and homogeneous catalysis. They delineate and quantify, which electronic properties of ancillary ligands are crucial for taming otherwise highly reactive terminal oxo intermediates. Notably, carbene ligands with both strong $\sigma$-donor and strong $\pi$-acceptor properties are best suited for the stabilization of palladium(॥) terminal oxo complexes, whereas ligands with a weaker ligand field lead to highly reactive complexes. Strongly donating ligands are an excellent choice for high-valent palladium(iv) terminal oxo compounds. Low coordinate palladium(॥) as well as high-valent palladium(IV) complexes are best suited for the activation of strong bonds.

\section{Introduction}

Oxo compounds of the late transition metals are alleged intermediates in fundamental chemical processes like the refinement of small molecules through redox catalysis. Prominent examples are the platinum catalyzed oxidation of ammonia to nitric acid by $\mathrm{O}_{2}$ (Ostwald process) or $\mathrm{CO} / \mathrm{NO}_{x}$ emission control in the catalytic converters of automobiles by palladium (rhodium, platinum) catalysis. ${ }^{1,2}$ Group 10 terminal oxo compounds (i.e., $\mathrm{M}(\mathrm{O})$ with $\mathrm{M}=\mathrm{Ni}, \mathrm{Pd}, \mathrm{Pt}$ ) hold therefore in analogy to the very rich $\mathrm{CH}$ oxidation chemistry of early transition metal oxo compounds great promise for selective $\mathrm{CH}$ activation or the splitting of water. ${ }^{3-15}$ The development of novel catalytic approaches in these areas is highly desirable in the context of green and sustainable oxidation catalysis. ${ }^{16-25}$ Collision experiments in the gas phase and computational studies established that naked oxides of the group 10 metals react even with methane to produce methanol. ${ }^{26-32}$ Importantly, these gas phase studies substantiate the intermediacy of terminal metal oxides both in heterogeneous as well as in homogeneous reaction media.

Friedrich-Alexander Universität Erlangen-Nürnberg, Egerlandstr. 1, 91058 Erlangen, Germany.E-mail: dominik.munz@fau.de

$\dagger$ Electronic supplementary information (ESI) available: Atomic coordinates, energies $(\Delta E, \Delta G)$, detailed benchmark tests (basis set, functional, corrections for dispersion and solvent effects), molecular orbital diagrams for $\mathbf{5}^{\mathbf{P d O}}$ and $\mathbf{1 0}^{\mathbf{P d O}}$, natural resonance theory results, details of CASSCF calculations, energies of isomers, other (non)linear correlations, calculation of TEP values and complete ref. 64. See DOI: 10.1039/c7sc05034h

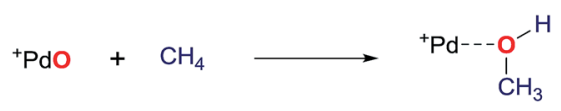

Accordingly, it was already proposed in the early 90s that palladium(Iv) terminal oxo compounds constitute intermediates of the oxy-insertion reaction of alkanes with peroxides in the liquid phase. ${ }^{33-37}$ High-valent nickel(III) ${ }^{38-42}$ and platinum(Iv) ${ }^{\mathbf{4 3}}$ (or surrogates, respectively) (4-46 $^{\mathbf{4}}$ terminal oxo species were equally suggested as intermediates for hydrocarbon functionalization chemistry. ${ }^{\mathbf{4 4 - 4 6}}$ It is well known that the isolation of such compounds is very challenging due to the population of anti-bonding molecular orbitals ("oxo wall" for $C_{4 \mathrm{v}}$ symmetry). ${ }^{47-51}$ The synthesis, characterization and study of room temperature stable group 10 terminal oxo compounds remains consequently elusive..$^{2,38,52-55}$ Nevertheless, Milstein and coworkers reported one surprising example, where a supposedly platinum(Iv) terminal oxo complex was stabilized by an NCP pincer ligand. Whereas the high reactivity of the complex prevented characterization by $\mathrm{X}$-ray crystallography, its oxygen transfer chemistry with carbon monoxide, phosphines, and dihydrogen could be evidenced. ${ }^{56}$

Even more surprisingly than the stability of the complex was the fact that the NCP pincer ligand did not feature strong $\pi$ backbonding capabilities. ${ }^{57}$ Up to this report, it was common believe that $\pi$-accepting ligands in a trigonal coordination environment should stabilize such compounds by releasing delectron density from the transition metal center, thereby reducing the electron repulsion between the metal d-electrons and the p-electrons of the oxo ligand. ${ }^{57,58}$ 

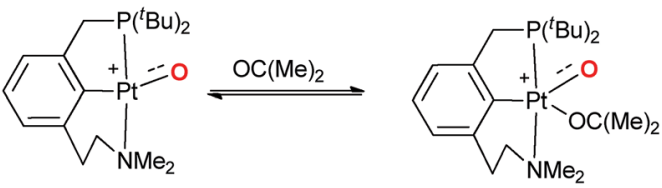

Later on, it was argued on the basis of computational investigations that both the excitation of d-electron density to sand p-orbitals as well as the coordination of acetone in solution could stabilize this particular complex by supporting out of plane bending of the oxo ligand. ${ }^{59}$ We conclude therefore that the electronic factors leading to highly reactive or comparably stable group 10 terminal oxo compounds are only poorly understood.

Herein, the influence of ancillary ligands on the electronic properties and thermodynamic stability of palladium complexes with terminal oxido ligands is elucidated computationally. ${ }^{57}$ Provided that enough thermodynamic stability can be achieved, sterically encumbering ligands should be able to kinetically protect these reactive species, i.e. increase the barrier for $\mathrm{O}$ atom transfer. ${ }^{60-62}$ Eventually, the isolation and study of a stable terminal oxo compounds will then open up new avenues towards rational catalyst design for various applications.

\section{Results and discussion}

First, high-level quantum chemical calculations on the NEVPT2/ $\operatorname{CASSCF}(8,8)$ level of theory will be used to reliably model the electronic properties of palladium terminal oxo complexes. Based on these results, a computationally more efficient approach using density functional theory (DFT) is applied. A series of palladium(II) and palladium(Iv) complexes with different monodentate ancillary ligands (amines, pyridines, phosphines, isocyanides, series of carbenes) will be investigated with the latter method. We will show that the thermodynamic stability as well as electronic properties of such palladium(II) terminal oxo complexes can be qualitatively rationalized through $\sigma$-donor $/ \pi$-acceptor effects of the ancillary ligand. The calculation of the related singlet/triplet gap of the complexes $\left(\mathrm{Pd}^{\mathrm{II}}\right)$ allows for a quantification of the reactivity of the terminal oxo moiety. Contrarily, we will show that the $\pi$-acceptor effects are not important for the $\mathrm{Pd}^{\mathrm{IV}}$ complexes, where the overall donor properties of the ancillary ligands determine the thermodynamic stability. Next, these results will be extended to chelating bidentate ligands and tricoordinate pincer-type ligands. Finally, overall trends in reactivity and electronic structure will be identified and implications for synthetic approaches will be discussed. ${ }^{63}$

\section{Computational methods}

All singlet and triplet geometry optimizations were performed with Gaussian09, Rev. D01 (ref. 64) at the B3LYP-D3(BJ)/def2TZVP $^{65-68}$ (valence triple- $\zeta$ plus single polarization basis set) ${ }^{69}$ level of theory using the def2 quasirelativistic effective core potential (ECP, 28 core electrons) and the related def2-TZVP valence basis set for palladium as obtained from the emsl basis set exchange data base ${ }^{\mathbf{6 9}, 70}$ and applying the D3 dispersion correction $^{71}$ with Becke-Johnson damping. ${ }^{72}$ The restricted formalism was used for closed-shell singlet multiplicities. No symmetry or internal coordinate constraints were applied during optimizations. All reported optimized structures were verified as true minima by the absence of negative eigenvalues in the harmonic vibrational frequency analysis and all wave functions were checked for undesired internal instabilities. The energies of all structures were corrected by single-point calculations with ORCA (version 3.0.3) on the B2PLYP(COSMO, D3BJ)/def2-TZVPP level of theory, including corrections for solvent effects (except the structures shown in Table 1) with the conductor like screening model COSMO ${ }^{73}$ (solvent: hexane). The RIJCOSX approximation was used to speed up the calculations. Test calculations revealed negligible deviation from calculations without the RIJCOSX procedure. Tighter than default scf convergence criteria (tightscf), and finer than default grids (grid5; finalgrid6) were used as implemented in ORCA. Structures optimized with B3LYP and B2PLYP showed very similar structural parameters. The chosen computational method was benchmarked for the influence of functional (B3LYP, PBE0, M06, M06L, B2PLYP, B2GP-BLYP, PWP-B95), basis set [def2SVP, def2-TZVP, def2-TZVPP, 6-31G(d), 6-311G(d,p), 6$311++G(d, p)]$ and dispersion and solvent corrections on experimental and computational results (structural parameters, multiplicities, energies) with Milstein's $\mathrm{Pt}^{\mathrm{IV}}$ complex $^{56,59}$ and Cundari's CASSCF $(8,8)$ study $^{\mathbf{4 4}}$ on truncated $\mathrm{Pd}^{\mathrm{IV}}$ bisimine complexes. For details, see the ESI. $\dagger$ Importantly, B3LYP, PBE0, M06 and M06L provided similar optimized structural parameters and consistent energy profiles, whereas it was found that triple- $\zeta$ basis sets are much better suited for the geometry optimizations than double- $\zeta$ basis sets. For energies of conformational and stereoisomers, see the ESI $\dagger$ as well. Structural optimizations using the complete active space SCF (CASSCF) method were performed with ORCA 3.0.3. Finer than default grid setting were chosen for the RIJCOSX approximation (IntAccX 4.34, 4.34, 4.67; GridX 2,2,2). The selection of the active space is delineated in more detail in the ESI. $\uparrow$ The def2-ECP and related def2-TZVPP valence basis set was used as implemented in ORCA for Pd in conjunction with the def2-TZVPP all-electron basis set for the other elements. Effects of dynamic electron correlation were included by the second order multireference perturbation method NEVPT2. ${ }^{74}$ The optimized CASSCF structures were verified as true minima through numerical calculation of the hessian. The DLPNO-CCSD(T) calculations ("NORMAL" settings) were performed accordingly on the DLPNO-CCSD(T)/def2-TZVPP//B3LYP/def2-TZVP level of theory using ORCA 4.0.1. All energies reported - except in Table 1, which shows electronic energies - are Gibbs free energies under standard conditions ( $T=298 \mathrm{~K}, p=1 \mathrm{~atm}$ ) using unscaled frequencies. Approximate Gibbs free energies were obtained through thermochemical analysis of the B3LYP-D3(BJ)/def2TZVP optimized structures, using the thermal corrections to the Gibbs free energy as reported by Gaussian09 (including zero-point effects, thermal enthalpy corrections, and entropy) and the electronic energy including solvent effects and 
dispersion corrections from the single point calculations with ORCA. For a comparison to $\Delta E$ values, which reflect the same trends, see the ESI. $\dagger$ The biradical open-shell singlet electronic states were obtained through the broken-symmetry formalism via the flip-spin procedure of ORCA with the optimized triplet structures. Spin-decontamination through the Yamaguchi formula ${ }^{75-77}$ did not have a considerable influence on the obtained energy differences. The nature of the open-shell biradical wave functions was verified using corresponding orbitals and spin populations. ${ }^{78}$ Natural Bond Orbitals (NBOs) were calculated with NBO 6.0. ${ }^{79}$ The energy decomposition analysis (EDA) and analysis of fragment molecular orbitals was performed with AOMix v6.88 based on wave functions computed with Gaussian09 on the B2PLYP(D3BJ)/def2-TZVPP//B3LYP-D3/def2TZVP level of theory. ${ }^{\mathbf{8 0 , 8 1}}$ The EDA decomposes the overall bonding interaction energy $\left(E^{\text {int }}\right)$ in orbital $\left(E^{\text {orb }}\right.$ : charge transfer and polarization effects) and steric contributions $\left(E^{\text {steric }}\right.$ : electrostatic and Pauli exchange energy). The Tolman electronic parameter of the CAAC, MIC, and DAC ligands were calculated according to Gusev's procedure with Gaussian09, rev. D01.82,83 Calculated structures, molecular orbitals and spin densities were visualized with IboView, ${ }^{84}$ Molden 5.6, ${ }^{85}$ and Avogadro $1.2 .0 .^{86}$

\section{Multireference character and perturbation theory results}

Computational modeling of late transition metal terminal oxo compounds is a challenge for single-determinantal DFT. ${ }^{87}$ In order to investigate the multireference character of a model $\mathrm{Pd}^{\mathrm{IV}}$ oxo complex with a truncated bisimine ligand (ethane-1,2dimine), a CASSCF $(8,8)$ study using the $6-31+G(d, p)$ basis set was reported. ${ }^{44}$ The calculations, which included the $\pi$-system of the imine ligand as well as the $\sigma$ - and one $\pi$-bond of the oxo ligand with the metal, suggested surprisingly that the molecule should have an open-shell singlet ground state. Indeed, we obtained even for the larger ligand with $N$-methyl substituents $\left(N^{1}, N^{2}\right.$-dimethyl ethane-1,2-dimine) as well an open-shell singlet ground state using the def2-SVP basis set (Table 1;

Table 1 Electronic structures of $\mathrm{Pd}^{\mathrm{IV}}$ terminal oxo complex with bisimine ligand (t: triplet; O.S.S.: open-shell singlet; s: closed-shell singlet) as predicted by $\operatorname{CASSCF}(8,8)$ and DFT. Electronic energies are given in $\left[\mathrm{kcal} \mathrm{mol}^{-1}\right]$
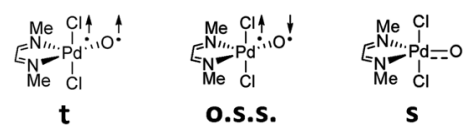

\begin{tabular}{|c|c|c|c|}
\hline$\Delta E$ CASSCF $(8,8) /$ def2-SVP & +2.0 & 0 & +6.3 \\
\hline$\Delta E$ CASSCF $(8,8) /$ def2-TZVPP & +3.1 & +2.3 & 0 \\
\hline$\Delta E \operatorname{CASSCF}(8,8) / \mathrm{NEVPT}^{a}{ }^{a}$ & +1.6 & +4.9 & 0 \\
\hline$\Delta E$ B2PLYP/def2-TZVPP & +1.6 & +6.9 & 0 \\
\hline$\Delta E \mathrm{~B} 2 \mathrm{PLYP} / / \mathrm{B} 3 \mathrm{LYP}{ }^{b}$ & +1.8 & +9.6 & 0 \\
\hline$\Delta E$ B3LYP/def2-TZVPP & -13.8 & n.d. & 0 \\
\hline$\Delta E$ DLPNO-CCSD(T)//B3LYP ${ }^{c}$ & 0 & n.d. & +4.7 \\
\hline
\end{tabular}
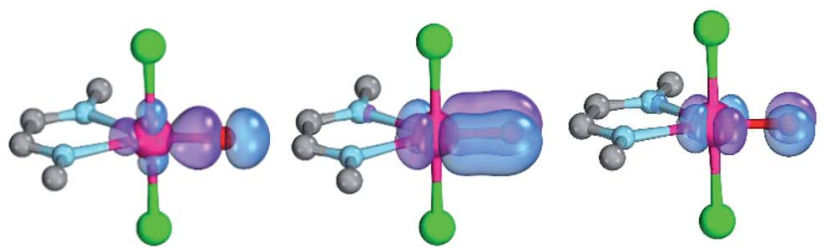

Fig. 1 CASSCF $(8,8)$ calculated coordination geometry and molecular orbitals for $\mathrm{Pd}^{\mathrm{IV}}$ complex with bisimine ligand in the singlet state (left to right: $\mathrm{Pd}-\mathrm{O} \sigma$-orbital, ON: 1.90; $\mathrm{Pd}-\mathrm{O} \pi$-orbital, ON: 1.78; $\mathrm{Pd}-\mathrm{O} \pi^{*}$ orbital; ON: 0.22). 
spin procedure as implemented in ORCA was used. Here, the stability of the open-shell singlet state was a bit underestimated supposedly due to the unrelaxed open-shell singlet structure $\left(\Delta E_{\text {o.s.s. }}=+9.6 \mathrm{kcal} \mathrm{mol}^{-1}\right)$.

Altogether, both DFT and CASSCF give coherent results and confirm that closed-shell singlet and triplet state energies are close in energy, with a closed-shell singlet ground state. Notably, also single-point calculations on the B2PLYP//B3LYP level of theory give reliable singlet/triplet gap energies. Therefore, all the following results refer to the latter level of theory. For further benchmarking studies relating to the choice of functional, basis set, and influence of dispersion and solvation effects, see the ESI (Fig. S1, Tables S1 and S2 $\dagger$ ).

Monodentate ligands. A series of electronically distinct ligands was chosen in order to evaluate the electronic influence of two-electron donor ("L-type") ligands on the properties of palladium terminal oxo complexes (Chart 1). Only ligands with well-developed synthetic procedures were investigated. Note that Hillhouse and Mindiola used chelating bis-NHC and bisphosphine ligands for the seminal synthesis of the isolobal nickel-imido complexes. ${ }^{\text {93-96 }}$ Likewise, N-donor ligands (Py, 1; $\mathrm{NMe}_{3}, 2$ ), which are commonly applied in oxidation catalysis as well as isonitriles ( $\mathrm{PhNC}, 3)$ and phosphines $\left(\mathrm{PMe}_{3}, 4\right)$ were included.

We anticipated that carbene ligands ${ }^{97-99}$ qualify as ideal candidates for two reasons. First, they are (unlike phosphines) typically stable under oxidative conditions. Second, there is a large variety of electronically distinct free carbenes beyond the very well-known imidazole-2-ylidenes (NHC, 5) available for the convenient synthesis of transition metal carbene complexes. Examples range from dihydroimidazole-2-ylidenes (saNHC, 6) and benzimidazolylidenes (benzNHC, 7) to mesoionic carbenes (MICs, 8), ${ }^{100,101}$ diamidocarbenes (DACs, 9) ${ }^{\mathbf{1 0 2}}$ and cyclic (alkyl)(amino) carbenes (CAACs, 10). ${ }^{\mathbf{1 0 3 , 1 0 4}}$ A popular method for the description of the donor properties of ligands is the Tolman electronic parameter (TEP). The TEP, which is obtained through determination of the $\mathrm{CO}$ stretching frequencies of $(\mathrm{L}) \mathrm{Ni}(\mathrm{CO})_{3}$ complexes, is related to the overall donor properties of a ligand and combines both $\sigma$ - and $\pi$-effects as well as steric contributions. ${ }^{105,106}$ According to the TEP, mesoionic carbene ligands (8), which do not show considerable $\pi$-accepting properties, are

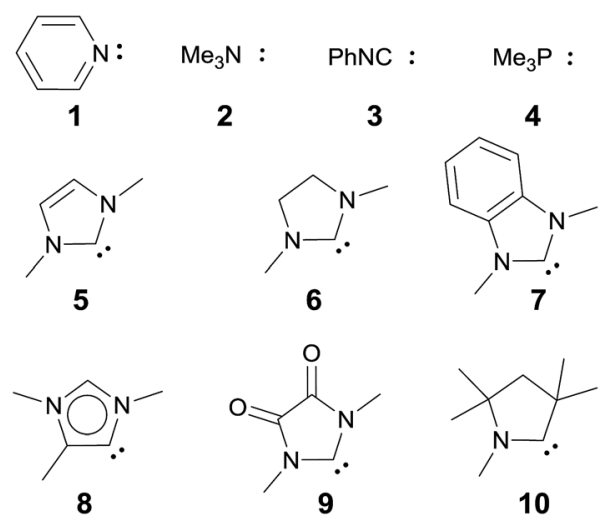

Chart 1 Evaluated monodentate ligands. exceptionally strong donor ligands. The electron deficient diamidocarbene 9 is expected by the TEP to be a very weak donor ligand. In extension, the ${ }^{13} \mathrm{C}$ and ${ }^{15} \mathrm{~N}$ NMR shifts of the free carbenes, ${ }^{107}{ }^{31} \mathrm{P}$ and ${ }^{77} \mathrm{Se}$ of phosphinidene and selenium adducts, ${ }^{108-110}$ and DFT calculations ${ }^{111-117}$ allowed for deconvolution of both $\sigma$-donor and $\pi$-acceptor effects.

Magnetic circular dichroism studies allowed to evaluate the influence of NHC ligands on the ligand field of iron(II) complexes. ${ }^{118,119}$ It has been reported that an ordering of both carbene ligands and $\mathrm{N}$-donor as well as P-donor ligands according to their ligand field is a challenging task due to side effects with the ancillary ligands. ${ }^{119}$ Nevertheless, it can be argued that CAAC (10) ligands with their very strong $\sigma$-donor and $\pi$-acceptor capabilities should be extraordinary strong field ligands. Consequently, benzNHCs (7, fairly strong $\sigma$-donor, fairly weak $\pi$-acceptor), NHCs $(5$, strong $\sigma$-donor, weak $\pi$ acceptor), and especially $\mathrm{N}$-donor $(\mathbf{1}, \mathbf{2})$ and P-donor ligands (4) should lead to smaller ligand field splittings. Optimizing the structures of the $\mathrm{LPd}^{\mathrm{II}} \mathrm{O}$ complexes with these monodentate ligands L (B2PLYP(COSMO,D3)/def2-TZVPP//B3LYP/def2-TZVP) reveals that the singlet states are lower in energy than the triplet states for all the investigated carbene ligands (vide infra). Strongly bent coordination geometries with short distances between the oxo moiety and the $N$-methyl substituents of the

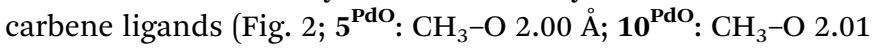
$\AA$ ) are predicted for all singlet state structures, whereas pseudolinear structures were optimized for the open-shell states (ESI $\dagger$ ). The linear coordination geometry represents however a transition state for the closed-shell molecules. The complex with an NHC ligand $\left(5^{\mathbf{P d O}}\right)$ shows a C-Pd-O angle of $107.7^{\circ}$ and the CAAC complex $\left(\mathbf{1 0}^{\mathbf{P d O}}\right)$ of $110.9^{\circ}$ (Fig. 2). The short distances between the oxo atom and the $N$-methyl substituents indicate weak hydrogen type bonding, which further stabilizes the terminal oxo group through delocalization of electron density. ${ }^{\mathbf{1 2 0 , 1 2 1}}$ Note that it has been shown that hydrogen bonding interactions can be crucial for the stabilization of terminal oxo groups. ${ }^{122}$ Most importantly, the computed $\mathrm{Pd}-\mathrm{O}$ bond length is predicted to be significantly shortened with 1.79 $\AA$ ( $\left.5^{\text {Pdo }}: 1.80 \AA\right)$ in comparison with crystallographically characterized $\mathrm{Pd}-\mathrm{O}$ single bonds, which are typically around 2.06 $\AA^{44}$

The shorter bond between the CAAC ligand and the palladium atom $(1.93 \AA)$ for $\mathbf{1 0}^{\mathbf{P d O}}$ in comparison to the NHC complex $5^{\text {Pdo }}(1.97 \AA)$ is indicative of stronger interaction between the metal atom and the carbene ligand (Fig. 3). The

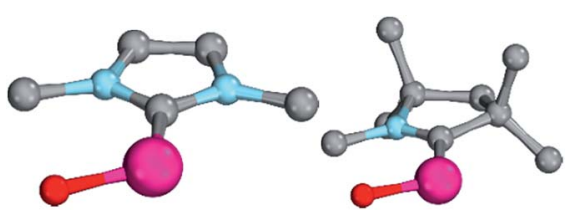

Fig. 2 Structural parameters of (NHC)PdO $\left(5^{\mathrm{PdO}}\right.$, left side) in comparison to (CAAC) PdO $\left(10^{\mathrm{PdO}}\right.$, right side) in the singlet states. $5^{\mathrm{PdO}}$ : $\mathrm{C}-\mathrm{Pd}-\mathrm{O} 107.7^{\circ}, \mathrm{Pd}-\mathrm{O} 1.80 \AA$ A $\mathrm{Pd}-\mathrm{C} 1.97 \AA$ A, $\mathrm{H}-\mathrm{O} 2.00 \AA$ A. $10^{\mathrm{PdO}}$ : C$\mathrm{Pd}-\mathrm{O}: 110.9^{\circ}, \mathrm{Pd}-\mathrm{O} 1.79 \AA \mathrm{A}, \mathrm{Pd}-\mathrm{C} 1.93 \AA$, $\mathrm{H}-\mathrm{O} 2.01 \AA$. 


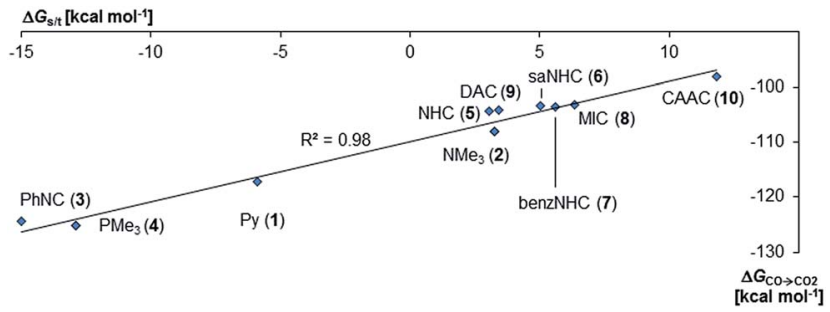

Fig. 3 Correlation of singlet/triplet gap $\left(\Delta G_{\mathrm{s} / \mathrm{t}}=G_{\text {triplet }}-G_{\text {singlet }}\right)$ of palladium(II) complexes with monodentate ancillary ligands with Gibbs free energy for the oxidation of $\mathrm{CO}$ to $\mathrm{CO}_{2}\left(\Delta G_{\mathrm{CO} \rightarrow \mathrm{CO}_{2}}\right)$ by the complexes in the singlet state.

Mayer bond indices for the $\mathrm{Pd}-\mathrm{O}$ bond indicate considerable multiple bond character $\left(5^{\mathrm{PdO}}: 1.47 ; \mathbf{1 0}^{\mathrm{PdO}}: 1.53\right)$ and are in good agreement with the natural atomic orbital Wiberg bond index for oxygen ( $\left.5^{\text {PdO }}: 1.40 ; 1^{\text {Pdo }}: 1.46\right)$. Natural resonance theory ${ }^{123}$ predicts as well a considerable double bond character (ESI, Fig. $\mathrm{S} 4 \dagger$ ), although the resonance weights for a double bond description are comparably small with $24 \%$ for a $\mathrm{Pd}=\mathrm{O}$ double bond for $5^{\mathbf{P d O}}$ and $23 \%$ for $\mathbf{1 0}^{\mathbf{P d O}}$, respectively.

Complementing the partial double bond character of the PdO bond, considerable negative partial charge is localized on the terminal oxo atom $\left(5^{\text {Pdo }}\right.$ : Löwdin: -0.48 a.u.; Hirshfeld: -0.60 a.u., NPA: -0.94 a.u.; $10^{\text {PdO }}$ : Löwdin: -0.50 a.u.; Hirshfeld: -0.62 a.u.; NPA: -0.95 a.u.). Also note the higher accumulation of positive charge on the palladium atom for $\mathrm{L}=\mathrm{CAAC} v \boldsymbol{s} . \mathrm{L}=$ NHC, which suggests enhanced relieve of d-electron density for 10 $^{\text {Pdo }}$.

(CAAC: Löwdin +0.14 a.u.; Hirshfeld: +0.35 a.u.; NPA: +0.64 a.u.; $5^{\text {Pdo }}$ : Löwdin: +0.12 a.u.; Hirshfeld: +0.33 a.u.; NPA: +0.62 a.u.). The computational results suggest hence a fairly strong electrostatic interaction between the palladium and oxygen atoms. The bond properties of the oxygen - palladium bonds were furthermore investigated by Morokuma's energy decomposition analysis (EDA), which decomposes the overall bonding interaction $\left(E^{\text {int }}\right)$ in orbital $\left(E^{\text {orb }}\right)$ and steric contributions $\left(E^{\text {steric }}\right) .{ }^{124-126}$ Indeed, the Pd-O bond (Table 2$)$ of $\mathbf{1 0}^{\text {PdO }}$ was found to be stronger $\left(E^{\text {int }}=-100.0 \mathrm{kcal} \mathrm{mol}^{-1}\right)$ than the one of the NHC complex $5^{\mathbf{P d O}}\left(E^{\mathrm{int}}=-97.2 \mathrm{kcal} \mathrm{mol}^{-1}\right)$, which vice versa suggests higher reactivity (i.e. lability of the $\mathrm{Pd}-\mathrm{O}$ bond) for the latter. Notably and in agreement with the analysis of the double bond character and geometrical parameters, this is mainly due to more favorable orbital interactions $\left(E^{\text {orb }}=\right.$ $-230.0 \mathrm{kcal} \mathrm{mol}^{-1}$ ) for the CAAC complex $\mathbf{1 0}^{\mathbf{P d O}}$ in comparison to the NHC analogue $5^{\text {Pdo }}\left(E^{\text {orb }}=-222.3 \mathrm{kcal} \mathrm{mol}^{-1}\right)$.

Table 2 Energy decomposition analysis ( $\left.E^{\text {int }}=E^{\text {orb }}+E^{\text {steric }}\right)$ of the palladium - oxygen bonds of (CAAC-Pd) $-\mathrm{O}\left(10^{\mathrm{PdO}}\right)$ and $(\mathrm{NHC}-\mathrm{Pd})-\mathrm{O}$ $\left(5^{\mathrm{PdO}}\right)$ in the closed-shell singlet states. Values are given in [kcal $\left.\mathrm{mol}^{-1}\right]{ }^{127}$

\begin{tabular}{llrlr}
\hline Fragments & Complex & $E^{\text {int }}$ & $E^{\text {orb }}$ & $E^{\text {steric }}$ \\
\hline (CAAC)Pd-O & $\mathbf{1 0}^{\text {PdO }}$ & -100.0 & -230.0 & +130.0 \\
(NHC)Pd-O & $\mathbf{5}^{\text {PdO }}$ & -97.2 & -222.3 & +125.1
\end{tabular}

The bonding interaction between the carbene ligands and the palladium monoxide molecular fragment in the closed-shell singlet state $\left(\left[{ }^{1} \Sigma^{+}\left(\pi^{* 4}\right)\right]\right)^{32}$ was as well investigated by energy decomposition (ESI, Table S3 $\dagger$ ). This approach corresponds to the picture of an "ancillary ligand stabilized palladium monoxide". The decomposition analysis suggests also for this covalent bond a stronger interaction between the CAAC and $\operatorname{PdO}\left(E^{\text {int }}=-65.8 \mathrm{kcal} \mathrm{mol}^{-1}\right)$ than for the NHC complex $\left(E^{\mathrm{int}}=\right.$ $-59.6 \mathrm{kcal} \mathrm{mol}^{-1}$ ).

The analysis of the Löwdin orbital population and the molecular orbital interaction diagram for $\mathbf{1 0}^{\text {PdO }}$ (ESI, Fig. S2†; fragments: PdO and the CAAC ligand) favor an overall $\mathrm{Pd}-\mathrm{O}$ bond order between one and two, with the occupation of two $\pi^{*}$ antibonding orbitals of the Pd-O bond. Moderate $(\approx 1$ a.u.) excitation of 4 d-electron density to the $5 \mathrm{~s}$ and $5 \mathrm{p}$ orbitals is predicted. The bent coordination geometry of the oxo ligand optimizes the bonding and antibonding interactions between the oxo p- and metal d-orbitals through mixing of the dorbitals. $^{39}$

The oxygen atom transfer to carbon monoxide (i.e. the oxidation of carbon monoxide to carbon dioxide) by the CAAC complex $10^{\mathrm{PdO}}$ proceeds highly exergonic $\left(\mathbf{1 0}^{\mathrm{PdO}}: \Delta G_{\mathrm{CO} \rightarrow \mathrm{CO}_{2}}=\right.$ -98.1 $\mathrm{kcal} \mathrm{mol}^{-1}$, Scheme 1) and therefore confirms that the complex is indeed a strong oxidant with strong $\mathrm{O}$-atom transfer capability.

Interestingly, the oxygen atom transfer from the NHC complex $5^{\mathrm{PdO}}$ proceeds even more exergonic $\left(5^{\mathrm{PdO}}: \Delta G_{\mathrm{CO} \rightarrow \mathrm{CO}_{2}}=\right.$ $-104.3 \mathrm{kcal} \mathrm{mol}^{-1}$ ). This is in perfect agreement with the analysis of the molecular orbital interactions and indicates that $\mathbf{5}^{\mathbf{P d O}}$ is more reactive than $\mathbf{1 0}^{\mathbf{P d O}}$. Markedly, the reduced exergonicity for the oxidation of CO by $\mathbf{1 0}^{\mathbf{P d O}}$ relative to the oxidation by $5^{\mathbf{P d O}}$ is also in line with the shorter Pd-O bond length (vide supra, $\mathbf{5}^{\mathbf{P d O}}, 1.80 \AA$; $\mathbf{1 0}^{\mathbf{P d O}}, 1.79 \AA$ ), which should be related with the palladium-oxo bond strength (Badger's rule) and the oxophilicity $^{38}$ of the (carbene)Pd fragment.

Next, the Gibbs free energy for the oxidation of $\mathrm{CO}$ to $\mathrm{CO}_{2}$ $\left(\Delta G_{\mathrm{CO} \rightarrow \mathrm{CO}_{2}}\right)$ was studied as well for all the other ligands shown in Chart 1. Remarkably, the very strong field CAAC ligand led to the least exergonic oxidation reaction $\left(\Delta G_{\mathrm{CO} \rightarrow \mathrm{CO}_{2}}=\right.$ $-98.1 \mathrm{kcal} \mathrm{mol}^{-1}$ ), i.e. the CAAC stabilizes the terminal oxo ligand the most (Fig. 3). The $\Delta G$ values for ligands with a supposedly weaker ligand field like pyridine $\mathbf{1}\left(\Delta G_{\mathrm{CO} \rightarrow \mathrm{CO}_{2}}=\right.$ $\left.-117.3 \mathrm{kcal} \mathrm{mol}^{-1}\right)$, the isonitrile ligand $3\left(\Delta G_{\mathrm{CO} \rightarrow \mathrm{CO}_{2}}=\right.$ $\left.-123.3 \mathrm{kcal} \mathrm{mol}{ }^{-1}\right)$ or the phosphine $\mathrm{PMe}_{3} 4\left(\Delta G_{\mathrm{CO} \rightarrow \mathrm{CO}_{2}}=\right.$

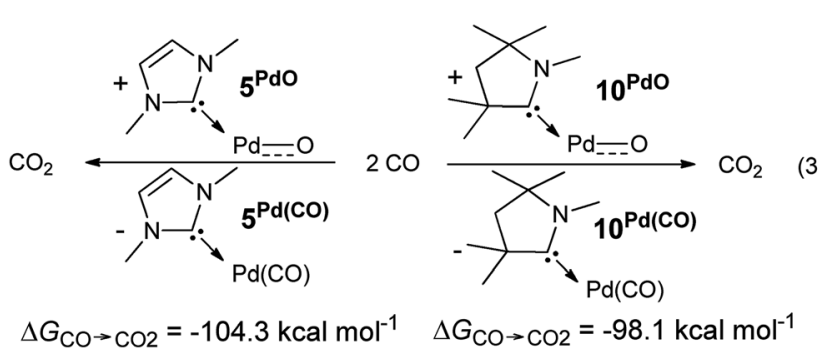

Scheme 1 Oxidation of $\mathrm{CO}$ to $\mathrm{CO}_{2}$ by palladium(॥) terminal oxo complexes $5^{\mathrm{PdO}}$ and $10^{\mathrm{PdO}}$. 
$-123.3 \mathrm{kcal} \mathrm{mol}^{-1}$ ) indicate thermodynamically much less stable terminal oxo complexes. The dihydroimidazolylidene (saNHC, 6) and benzimidazolylidene (benz-NHC, 7) ligands with their moderate $\pi$-accepting properties were predicted - in perfect agreement with the expectations - to be between the imidazolylidene (NHC, 5) and the CAAC ligand (10).

Next, a general method, which quantifies the ancillary ligand effects and therefore allows for the prediction of the thermodynamic stability of terminal oxo complexes, was sought. We anticipated that the singlet/triplet gap of terminal oxo compounds should be related to the stability of the complexes, because the excitation of the singlet into the triplet state is associated with transition from partial $\mathrm{Pd}=\mathrm{O}$ multiple bond character to a single bond (vide supra).

Looking into the literature corroborates as well that thermodynamic considerations or respectively the singlet/triplet gap of a transition metal oxo complex could be a good indicator for its reactivity. It has been experimentally shown that the rate as well as the thermodynamics of $\mathrm{CH}$ activation by $\mathrm{Fe}^{\mathrm{IV}}$ terminal oxo complexes with bispidine ligands are mainly dependent on the energy required for the spin-state crossover from $S=1$ to $S=2 .{ }^{128}$ It was also proposed for iron(Iv) model complexes that weak field ligands should lead to higher reaction rates for the activation of $\mathrm{CH}$ bonds. ${ }^{129,130}$ Equally, it was shown computationally for late transition metal amido and alkoxo compounds that ground state effects (i.e. the stability of the metal starting material) can be more important for $\mathrm{CH}$ activation reactivity than transition state effects. ${ }^{\mathbf{1 3 1 , 1 3 2}}$ Schwarz concluded that the spin state and more precisely spin density on terminal oxyl moieties is important for an efficient hydrogen atom abstraction from hydrocarbons in the gas phase. ${ }^{\mathbf{1 3 3}}$ Calculations by Ziegler suggested that thermodynamics as well as the HOMO-LUMO gap are important for the $\mathrm{CH}$ and $\mathrm{OH}$ activation reactivity of a chosen set of group 5-8 terminal oxo complexes. ${ }^{134}$

Indeed, the TEP, HOMO/LUMO energy levels of the ligands or partial charges of the coordinating carbene ligands ( $\mathrm{Pd}, \mathrm{O}$ atoms) are not very good indicators (ESI; Fig. S5-S7†) for the thermodynamic stability of the terminal oxo ligand. Contrarily, the $\Delta G$ value for the oxidation of carbon monoxide to carbon dioxide $\left(\Delta G_{\mathrm{CO} \rightarrow \mathrm{CO}_{2}}\right)$ is related with the singlet/triplet gap $\left(\Delta G_{\mathrm{s} / \mathrm{t}}\right)$ of the LPdO complexes (Fig. 3). ${ }^{135}$ Supposedly weaker field ligands stabilize the triplet over the singlet state $\left(\right.$ e.g., $3^{\text {Pdo }}: \Delta G_{\mathrm{s} / \mathrm{t}}$ $=-15.0 \mathrm{kcal} \mathrm{mol}^{-1}$ ) and lead therefore to more reactive terminal oxo species. Strong field ligands like $N$-heterocyclic

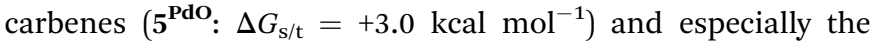
CAAC ligand $\left(\mathbf{1 0}^{\mathbf{P d O}} \Delta G_{\mathrm{s} / \mathrm{t}}=+11.8 \mathrm{kcal} \mathrm{mol}^{-1}\right)$ stabilize the singlet state and accordingly the terminal oxo ligand. The openshell singlet states (o.s.s.) are predicted to not be energetically competitive with the closed-shell singlet state for most strong

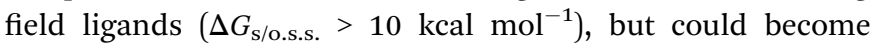
important for some of the weaker field ligands with a triplet ground state $\left(\Delta G_{\text {s/o.s.s. }}<10 \mathrm{kcal} \mathrm{mol}^{-1}\right.$ for 1, 3, 4; ESI, Table S5 $\left.\dagger\right)$.

When looking at the corresponding $\mathrm{Pd}^{\mathrm{IV}}$ complexes with two chlorido ligands, the triplet state becomes more stable than the closed-shell singlet state for all investigated ligands. The geometry optimizations reveal that the chlorido ligands are positioned perpendicular to the carbene $\mathrm{p}_{\mathrm{z}}$ orbital, thereby minimizing interaction between the potentially $\pi$-acidic carbene ligand and the transition metal (Fig. 4).

In addition, the elongation of the carbene palladium bond to $2.03 \AA$ suggests negligible $\pi$-backbonding from the transition metal to the carbene ligand. Accordingly, the NHC complex $5^{\mathbf{P d C l}_{2} \mathrm{O}}$ features a pseudo square planar coordination geometry with a still short Pd-O bond (1.84 $\AA$ ), but a Mayer bond index of only 0.9 (Fig. 4, left side). The two unpaired electrons are localized on the oxygen and palladium atom, respectively, with only very few delocalization onto the carbene atom. This picture is complemented by the calculated partial charges on the palladium and oxygen atoms, respectively, which indicate less zwitterionic character as was predicted for the corresponding palladium(II) complexes (Löwdin partial charges for $5^{\mathbf{P d C l}_{2} \mathbf{O}}$ : $\mathrm{O}$, +0.12 a.u.; $\mathrm{Pd},-0.32$ a.u.). The open-shell singlet state, which was calculated using the broken-symmetry formalism, is considerably higher in energy $\left(\Delta G_{\mathrm{t} / \text { o.s.s. }}=9.8 \mathrm{kcal} \mathrm{mol}^{-1}\right)$ and shows a similar spin density map like the triplet ground state (Fig. 4, right side). The reactivity of the palladium(Iv) oxo complex $5^{\mathbf{P d C l}_{2} \mathbf{O}}$ is of course higher $\left(\Delta G_{\mathrm{CO} \rightarrow \mathrm{CO}_{2}}=\right.$ $-113.7 \mathrm{kcal} \mathrm{mol}^{-1}$ ) than the palladium(II) oxo complex $5^{\mathbf{P d o}}$ $\left(\Delta G_{\mathrm{CO} \rightarrow \mathrm{CO}_{2}}=-104.3 \mathrm{kcal} \mathrm{mol}^{-1}\right)$.

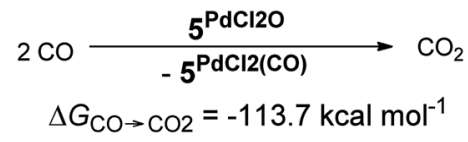

The overall oxidation strength of the palladium(Iv) complexes with the carbene ligands seems to be correlated with the overall donor strength of the carbene ligand as obtained by the Tolman electronic parameter (ESI, Fig. S8 $\dagger$ ). However, the influence is small with $\Delta \Delta G_{\mathrm{CO} \rightarrow \mathrm{CO}_{2}}<4 \mathrm{kcal} \mathrm{mol}^{-1}\left(3^{\mathbf{P d C l}_{2} \mathbf{O}}\right.$ : -115.4 kcal mol ${ }^{-1} ; \mathbf{8}^{\mathbf{P d C l}_{2} \mathbf{O}}$ : -112.1 $\left.\mathrm{kcal} \mathrm{mol}^{-1}\right)$ for all carbene ligands. Note the analogy with chromium(v) nitrido complexes with weak ancillary ligands, where it has been shown that the molecular orbital energies are dominated by the $\{\mathrm{CrN}\}^{2+}$ unit. ${ }^{136,137}$

Bidentate ligands. A series of chelating ligands was investigated in order to verify whether the correlations found for the monodentate ligands apply also for the estimation of the stability of palladium terminal oxo complexes with bidentate ligands (Chart 2). ${ }^{\mathbf{1 3 8 , 1 3 9}}$

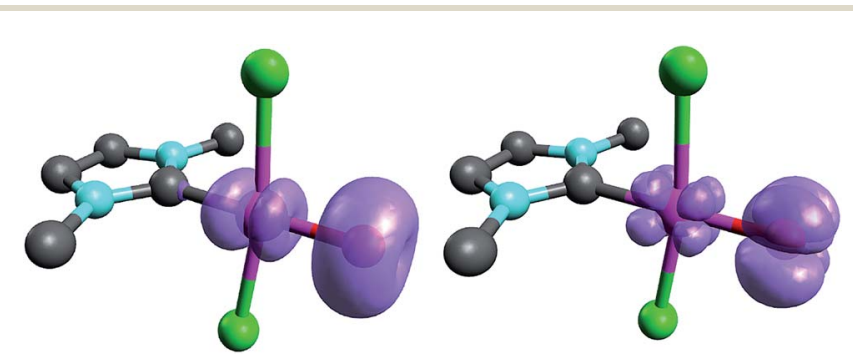

Fig. 4 Structural parameters $\left(\mathrm{C}-\mathrm{Pd}-\mathrm{O} 180.0^{\circ}, \mathrm{Pd}-\mathrm{O} 1.84 \AA, \mathrm{Pd}-\mathrm{C}\right.$ $2.03 \AA$ ) and spin density of $\mathrm{NHC}$ complex $5^{\mathrm{PdCl}_{2} \mathrm{O}}$ in the triplet state (left side) and open-shell singlet state (right side). 


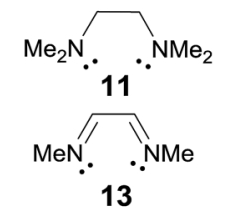

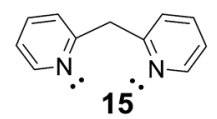<smiles>C[Pb]CCC[Pb]</smiles><smiles>CN1CCN(CN2C=NC(=O)C2)C1</smiles>

19<smiles></smiles>

21<smiles>[R16][C@@H]1[C@H](C[C@]2(C)CN(C)C(C)(C)C2)CC1(C)C</smiles>
$23 a, b$<smiles></smiles><smiles></smiles>

27

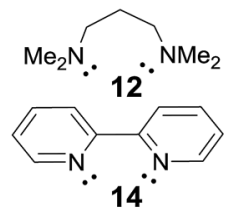

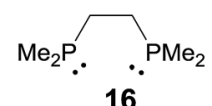
16<smiles></smiles>
18<smiles></smiles><smiles>[Z20]C1N(C)C(=O)C(=O)N1CN1[C]N(C)C(=O)C1=O</smiles><smiles>CC1(C)CN(CN2C=CC(C)(C)C2(C)C)C(C)(C)C1</smiles>

24

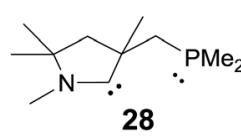

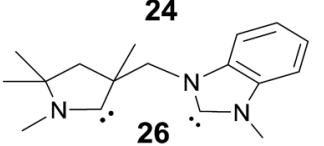

Chart 2 Evaluated bidentate ligands.

Indeed, we observed the very same trends and behavior for the bidentate ligands. Again, the molecules are expected to have a singlet ground state $e . g$., a $\Delta G_{\mathrm{s} / \mathrm{t}}$ of more $32 \mathrm{kcal} \mathrm{mol}^{-1}$ was predicted for the CAAC complex 24 (Fig. 5). The singlet diradical electronic state was confirmed to not be important for all carbene ligands (ESI, Table S7 $\dagger$ ). The calculations predict as well a correlation between $\Delta G_{\mathrm{s} / \mathrm{t}}$ and $\Delta G_{\mathrm{CO} \rightarrow \mathrm{CO}_{2}}$. Importantly, the CAAC complexes $\left(\mathbf{2 3}{ }^{\mathbf{P d O}}, \mathbf{2 4}^{\mathbf{P d O}}\right)$ are the most stable species, whereas the other carbene ligands and especially the $\mathrm{N}$-donor ligands lead to much higher reactivity. Looking at the molecular structures of the complexes reveals in most cases similar structural parameters as were found for the monodentate

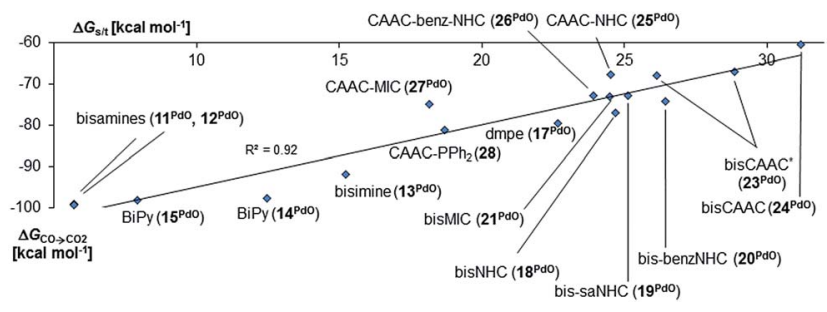

Fig. 5 Correlation of singlet/triplet gap $\left(\Delta G_{\mathrm{s} / \mathrm{t}}=G_{\text {triplet }}-G_{\text {singlet }}\right)$ of complexes with chelating ancillary ligands with Gibbs free energy for the oxidation of $\mathrm{CO}$ to $\mathrm{CO}_{2}\left(\Delta G_{\mathrm{CO} \rightarrow \mathrm{CO}_{2}}\right)$ by the complexes in the singlet state. ${ }^{140}$

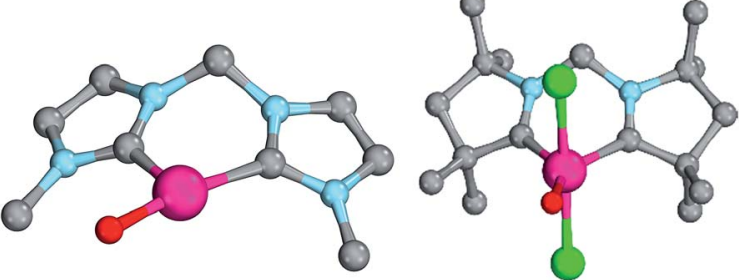

Fig. 6 Structural parameters of $18^{\mathrm{PdO}}$ (left side) and of $24^{\mathrm{PdO}}$ (right side) in the singlet states. $18^{\mathrm{PdO}}: \mathrm{C} 1-\mathrm{Pd}-\mathrm{O} 102.0^{\circ}, \mathrm{Pd}-\mathrm{O} 1.83 \AA \mathrm{Ad}-$ $\mathrm{C} 11.96 \AA \AA \mathrm{Pd}-\mathrm{C} 22.04 \AA$, O-C $1.94 \AA$ A. $24^{\mathrm{PdO}}$ : C1-Pd-O 138.0, $\mathrm{Pd}-\mathrm{O}$ $1.80 \AA, P d-C 11.94 \AA$, Pd-C2 $1.94 \AA$.

ligands (Fig. 6, left side). The calculations predict T-shaped coordination geometries with a weak interaction between the $N$-methyl substituents and the terminal oxo ligand (1.94 $\AA$ ).

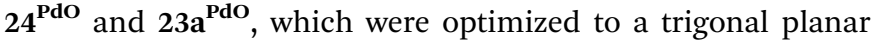
coordination geometry, are the most stable structures.

All attempts to optimize trigonal planar coordination geometries for the other carbene ligands led to transition state structures, whereas optimizations of a T-shaped geometry for $\mathbf{2 4}^{\text {Pdo }}$ evolved to be unstable. Notably, of the two diastereomers

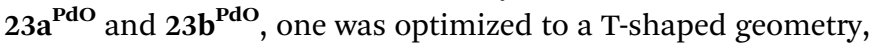
whereas the other one features a trigonal planar coordination geometry. Looking at the bond lengths of the $\mathrm{Pd}-\mathrm{O}$ bond suggests slightly reduced double bond character for the bisNHC complex $18^{\mathrm{PdO}}(\mathrm{Pd}-\mathrm{O}: 1.83 \AA$ ) in relation to the bisCAAC complex $24^{\text {PdO }}$ (Pd-O: $1.80 \AA$ ) or the complexes with monodentate ligands (5 ${ }^{\text {Pdo }}: 1.80 \AA$ А 10 $^{\text {Pdo }}: 1.79 \AA$; vide supra). The Mayer bond index predicts however the double bond character of the palladium oxygen bond to be slightly higher for the bidentate ligands $\left(\mathbf{1 8}^{\mathrm{PdO}}\right.$ : $\left.1.50 ; \mathbf{2 4}^{\mathrm{PdO}}: 1.63\right)$. The electrostatic interactions between the palladium atoms and oxo ligands (Löwdin partial charges for $18^{\mathrm{PdO}}$ : Pd, +/-0.00 a.u.; O, -0.64 a.u.; $24^{\text {Pdo }}$ : Pd, +0.06 a.u.; O, -0.63 a.u.) are larger for the bidentate than the monodentate ligands $\left(5^{\mathrm{PdO}}: \mathrm{Pd},+0.12\right.$ a.u.; O: -0.48 a.u., vide supra). Looking at the $\mathrm{Pd}-\mathrm{O}$ bond by energy decomposition analysis (Table 3) confirms a stronger bonding interaction for the trigonal planar bisCAAC complex $\mathbf{2 4}^{\mathbf{P d O}}\left(E^{\mathrm{int}}\right.$ $=-154.3 \mathrm{kcal} \mathrm{mol}^{-1}$ ) than for the T-shaped bisNHC complex $\left(E^{\text {int }}=-140.2 \mathrm{kcal} \mathrm{mol}^{-1}\right)$. Note that this time the steric repulsion energy $\left(\mathbf{2 4}^{\mathrm{PdO}}, E^{\text {steric }}=+61.8 \mathrm{kcal} \mathrm{mol}^{-\mathbf{1}} ; \mathbf{1 8}^{\mathbf{P d O}}, E^{\text {steric }}\right.$

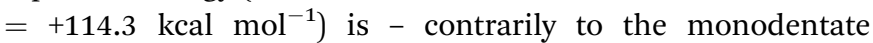
complexes - much smaller for the bisCAAC complex $\mathbf{2 4}^{\mathbf{P d O}}$. Apparently the trigonal planar coordination geometry leads to

Table 3 Energy decomposition analysis $\left(E^{\text {int }}=E^{\text {orb }}+E^{\text {steric }}\right)$ of the palladium - oxygen bonds of the bisCAAC complexes $24^{\mathrm{PdO}}, 23 \mathrm{a}^{\mathrm{PdO}}$, $23 \mathrm{~b}^{\mathrm{PdO}}$ and the bis NHC complex $17^{\mathrm{PdO}}$ in the singlet states. Values are given in $\mathrm{kcal} \mathrm{mol}^{-1}$

\begin{tabular}{lllr}
\hline & $E^{\text {int }}$ & $E^{\text {orb }}$ & \multicolumn{1}{c}{$E^{\text {steric }}$} \\
\hline $\mathbf{2 4}^{\text {Pdo }}(\mathrm{L}=$ bisCAAC; trigonal planar $)$ & -154.3 & -216.1 & +61.8 \\
$\mathbf{2 3 a}^{\mathbf{P d O}}(\mathrm{L}=$ bisCAAC, trigonal planar $)$ & -146.7 & -225.2 & +78.5 \\
$\mathbf{2 3 b}^{\mathbf{P d o}}(\mathrm{L}=$ bisCAAC, T-shaped $)$ & -147.5 & -249.1 & +101.6 \\
$\mathbf{1 8}^{\mathbf{P d O}}(\mathrm{L}=$ bisNHC$)$ & -140.2 & -254.5 & +114.3
\end{tabular}


combined reduced repulsive electrostatic and Pauli interactions, albeit at the cost of likewise reduced orbital stabilization $\left(E^{\text {orb }}=-216.1 \mathrm{kcal} \mathrm{mol}^{-1}\right)$. Looking at the isomeric bisCAAC

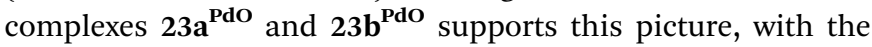
trigonal planar coordination geometry showing much smaller steric repulsion energy $\left(\mathbf{2 3 a} \mathbf{a}^{\mathbf{P d O}}\right.$, trigonal planar, $E^{\text {steric }}=$

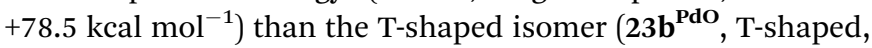
$\left.E^{\text {steric }}=+101.6 \mathrm{kcal} \mathrm{mol}^{-1}\right)$. It was investigated, if the bidentate carbene ligands stabilize the palladium oxo species in the $+\mathrm{IV}$ oxidation state as well. The calculations predict the closed-shell singlet states to be more stable than the triplet states by at least $\Delta G_{\mathrm{s} / \mathrm{t}}>8.5 \mathrm{kcal} \mathrm{mol}^{-1}$ for all carbene ligands; note that for amine, imine, and phosphine ligands smaller singlet/triplet gaps were obtained (vide supra; ESI, Table S8†). The openshell singlet states for the complexes with carbene ligands are predicted to be in most cases considerably higher in energy than the closed-shell singlet states $\left(\Delta G>12 \mathrm{kcal} \mathrm{mol}^{-1}\right)$. All carbene complexes show trigonal-bipyramidal coordination geometries with the chlorido ligands in the apical positions (Fig. 7).

As indicated by the Mayer bond indices and in agreement with the $\operatorname{CASSCF}(8,8)$ results for the bisimine ligand, the $\mathrm{Pd}-\mathrm{O}$ bond shows still fairly strong double bond character $\left(\mathbf{1 8}^{\mathbf{P d C l}_{2} \mathbf{O}}\right.$ : 1.40). Nevertheless, the zwitterionic character of the $\mathrm{Pd}-\mathrm{O}$ bond is reduced through negative charge transfer from the chlorido ligands to the metal center (Löwdin partial charges for $\mathbf{1 8}^{\mathbf{P d C l}_{2} \mathbf{O}}$ : $\mathrm{Pd},-0.23 ; \mathrm{O},-0.41)$. In fact, the $\mathrm{Pd}-\mathrm{O}$ bond is modeled to be of similar length like the singlet ground state monodentate palladium(II) complex $5^{\mathbf{P d C l}_{2} \mathbf{O}}(1.80 \AA)$.

In agreement with the calculations on the triplet state of the mono coordinated palladium(Iv) complexes, no correlation between $\Delta G_{\mathrm{s} / \mathrm{t}}$ and of $\Delta G_{\mathrm{CO} \rightarrow \mathrm{CO}_{2}}$ could be found. However, the Tolman electronic parameter TEP seems to be fairly well correlated to the oxidation strength of the terminal oxo $\mathrm{Pd}^{\mathrm{IV}}$ complex for the carbene ligands (Fig. 8). We conclude accordingly, that the stability of the singlet palladium(Iv) terminal oxo complexes is rather dominated by the stabilization of the highvalent metal center, instead of orbital interactions with the oxo ligand. Notably, the Gibbs free enthalpy for the oxidation of the $\mathrm{Pd}^{\mathrm{II}} \mathrm{Cl}_{2}$ complexes to the respective $\mathrm{Pd}^{\mathrm{IV}} \mathrm{OCl}_{2}$ compounds by dimethyl dioxirane (DMDO) ranges from -2 to $+9 \mathrm{kcal} \mathrm{mol}^{-1}$ (ESI, Fig. S12 $\dagger$ ). This suggests that the experimental isolation of such a complex should be possible.

Tridentate ligands. Finally also tridentate ligand systems were evaluated with a focus on carbene donor ligands. ${ }^{\mathbf{1 4 2 , 1 4 3}}$ Pyridine bridged biscarbenes (-pyridines, -imines) were

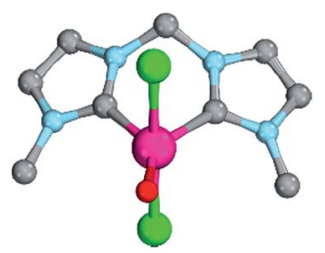

Fig. 7 Structural parameters of $18^{\mathrm{PdCl} 2 \mathrm{O}}$ in the singlet state. $\mathrm{C}-\mathrm{Pd}-\mathrm{O}$ $140.0^{\circ}, \mathrm{Pd}-\mathrm{O} 1.79 \AA \mathrm{Pd}-\mathrm{C} 2.05 \AA$.

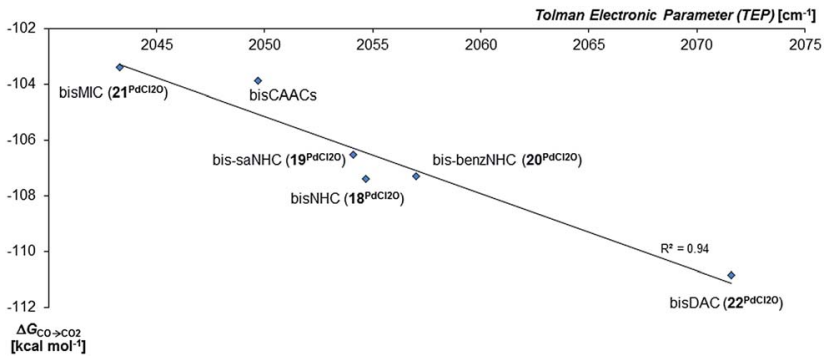

Fig. 8 Correlation of the Gibbs free energy for the oxidation of $\mathrm{CO}$ to $\mathrm{CO}_{2}\left(\Delta \mathrm{G}_{\mathrm{CO} \rightarrow \mathrm{CO}_{2}}\right)$ by the palladium(Iv) complexes with bidentate carbene ligands in the singlet state with the Tolman Electronic Parameter TEP (donicity). ${ }^{141}$ The values of the bisCAAC complexes $23^{\text {PdCl2O }}$ and $24^{\mathrm{PdCl} O \mathrm{O}}$ are averaged.

investigated for the oxidation state + II and following Milstein's experimental work ${ }^{56}$ phenylene bridged pincer ligands for the oxidation state + IV (Chart 3).

Enhanced electron donation from three L donor ligands in comparison to the bidentate coordination geometries leads to an elongation of the $\mathrm{Pd}-\mathrm{O}$ bonds for the singlet-state palladiu$\mathrm{m}$ (II) complexes (Fig. 9; 31 ${ }^{\text {PdO }}$ : $1.86 \AA$ ) and a reduction of the Mayer bond order (1.21) in comparison to the bidentate ligand (vide supra). The charge separation within the $\mathrm{Pd}-\mathrm{O}$ bond was found to be slightly larger (Löwdin partial charges for $31^{\mathbf{P d O}}$ : O, -0.68 a.u.; Pd, -0.02 a.u.). Again, weak hydrogen bonding type interactions were found between the $N$-methyl substituents and the terminal oxo ligand.

Surprisingly, the Gibbs free energy of the oxidation of $\mathrm{CO}$ to $\mathrm{CO}_{2}\left(\Delta G_{\mathrm{CO} \rightarrow \mathrm{CO}_{2}}\right)$ do not follow the same order as was obtained<smiles>[Y]1c(-c2ccccn2)cccc1-c1ccccn1</smiles>

29<smiles></smiles><smiles>CN1[C]N(c2cccc(N3CN(C)c4ccccc43)n2)c2ccccc21</smiles><smiles></smiles>

35

$\mathrm{Y}=\mathrm{N}, \mathrm{C}$<smiles>CN=C(C)c1[Y]c(C(C)=NC)ccc1</smiles>

30<smiles>CN1CCN(c2[Y]c(N3CCN(C)C3)ccc2)C1</smiles><smiles></smiles>

34<smiles>CC1(C)CN(c2[Y]c(N3CC(C)(C)CC3(C)C)ccc2)C(C)(C)C1</smiles>

Chart 3 Evaluated tridentate ligands. 


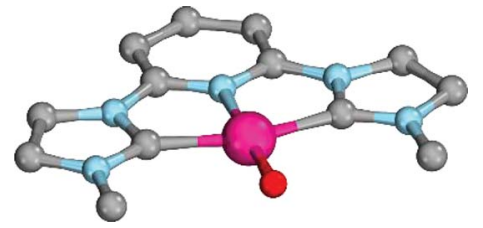

Fig. 9 Structural parameters of $31^{\mathrm{PdO}}$ in the singlet ground state. C$\mathrm{Pd}-\mathrm{O} 101.6^{\circ}, \mathrm{Pd}-\mathrm{O} 1.86 \AA$, Pd-C $2.01 \AA$.

for the monodentate and bidentate cases. Whereas once more the stability of the palladium oxo compounds seems to be quite well correlated with the singlet/triplet gap of the complexes, the $\pi$-acidic CAAC ligand leads this time to a much more reactive compound than both the very electron rich mesoionic carbene $\left(\mathbf{3 4}^{\mathbf{P d O}}\right)$ or the very electron poor diamidocarbene $\left(\mathbf{3 5}^{\mathbf{P d O}}\right)$ ligand (Fig. 10).

Examination of the triplet state wave functions reveals that the electronic structures of all these compounds show strong delocalization of spin density from the metal onto the pincer ligand (Fig. 11, left side). ${ }^{\mathbf{1 4 4 , 1 4 5}}$ Whereas both the monodentate NHC complex $5^{\mathbf{P d O}}$ (Fig. 4) and the bidentate complex $\mathbf{1 8}^{\mathbf{P d O}}$ (Fig. 6, left side) show localization of most spin density on the metal center with some delocalization onto the carbene atom, the complex $\mathbf{3 1}^{\mathbf{P d O}}$ involves a mainly pyridine centered radical with only few spin density on the metal atom (Fig. 11, left side). Therefore, simple donor-acceptor considerations are not an appropriate tool to explain reactivity trends. However, the relation shown in Fig. 10 strongly suggests that redox active ligands can be harnessed for the stabilization of terminal oxo complexes.

Looking at the pincer ligands with palladium in the oxidation state of +IV reveals that the triplet multiplicity should be more stable than the singlet state, albeit by less than $10 \mathrm{kcal} \mathrm{mol}^{-1}$ (ESI, Table S11†). The open-shell singlet biradicals are expected to be only slightly higher in energy than the triplet biradicals and in the same order of magnitude like the closed-shell singlet states (roughly $10 \mathrm{kcal} \mathrm{mol}^{-1}$ higher than the triplet states; ESI, Table S11 $\dagger$ ). The influence of the specific pincer ligand on the oxidation of $\mathrm{CO}$ to $\mathrm{CO}_{2}\left(\Delta G_{\mathrm{CO} \rightarrow \mathrm{CO}_{2}}\right)$ seems to be less important than for the neutral palladium(Iv)

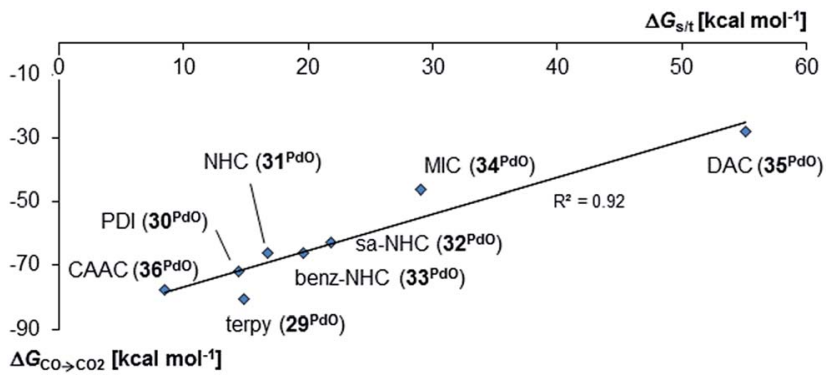

Fig. 10 Correlation of singlet/triplet gap $\left(\Delta G_{s / t}=G_{\text {triplet }}-G_{\text {singlet }}\right)$ of palladium(॥) complexes with tridentate ligands with Gibbs free energy for the oxidation of $\mathrm{CO}$ to $\mathrm{CO}_{2}\left(\Delta \mathrm{G}_{\mathrm{CO} \rightarrow \mathrm{CO}_{2}}\right)$ by the complexes in the singlet state.

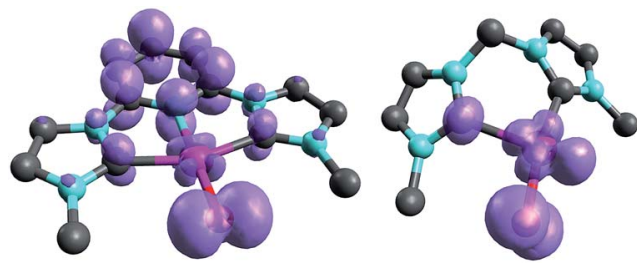

Fig. 11 Spin densities of NHC complex $31^{\mathrm{PdO}}$ (left side) and $18^{\mathrm{PdO}}$ (right side) in the triplet states.

complexes with bidentate ligands (Fig. 12; e.g. 30 $^{\mathbf{P d O}+}: \Delta G_{\mathrm{CO} \rightarrow}$ $\mathrm{CO}_{2}=-111.8 \mathrm{kcal} \quad \mathrm{mol}^{-1} ; \quad 34^{\mathrm{PdO}+}: \Delta G_{\mathrm{CO} \rightarrow \mathrm{CO}_{2}}=$ $\left.-107.6 \mathrm{kcal} \mathrm{mol}^{-1}\right)$.

$$
\begin{gathered}
2 \mathrm{CO} \underset{-31^{\mathrm{PdO}+}}{-\frac{31^{\mathrm{Pd}(\mathrm{CO})+}}{\longrightarrow}} \mathrm{CO}_{2} \\
\Delta G_{\mathrm{CO} \rightarrow \mathrm{CO} 2}=-109.0 \mathrm{kcal} \mathrm{mol}^{-1}
\end{gathered}
$$

Nevertheless, there seems to be again a tentative connection between the overall donicity of the ligands, i.e. the Tolman electronic parameter, and the thermodynamic stability of the palladium terminal oxo complexes (Fig. 12). The correlation is in fact surprisingly good, considering that the TEP includes steric contributions and that it has been noted that values from different families of ligands (C-donor, N-donor, P-donor) can usually not be compared.

Table 4 shows a summary of the most important trends for the different evaluated ligand systems and oxidation states. As can be seen, the stability of the palladium(II) complexes as well as the $\mathrm{Pd}-\mathrm{O}$ bond length increases with the number of ancillary $\mathrm{L}$ type ligands. A closed shell singlet ground state was found for almost all complexes in the oxidation state of + II and the oxidation strength is correlated with the singlet/triplet gap of the terminal oxo complexes. For the palladium(Iv) complexes, various electronic ground states (closed-shell singlet, open-shell singlet, triplet) are possible in dependence of the ancillary ligands. Notably, the oxidation strength of these complexes seems not to be dependent on the singlet/triplet gap of the particular complex, but rather the overall donor capabilities of ancillary ligands. Furthermore, an overall cationic charge as modeled with the $\mathrm{L}_{2} \mathrm{X}$ pincer ligands seems to enhance the reactivity of these complexes. We predict therefore that

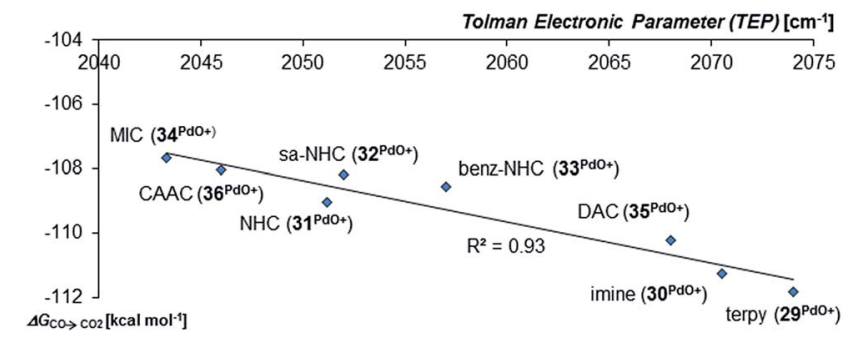

Fig. 12 Correlation of the Tolman Electronic Parameter TEP (donicity) with Gibbs free energy for the oxidation of $\mathrm{CO}$ to $\mathrm{CO}_{2}\left(\Delta \mathrm{G}_{\mathrm{CO} \rightarrow \mathrm{CO}_{2}}\right)$ by the cationic $\mathrm{Pd}^{\mathrm{IV}}$ pincer complexes in the triplet state. ${ }^{48}$ 
Table 4 Comparison of different ligand systems containing the imidazolylidene group

\begin{tabular}{|c|c|c|c|c|c|}
\hline $\begin{array}{l}\text { Oxidation } \\
\text { state }\end{array}$ & Ligand & Spin state & $\begin{array}{l}\Delta G_{\mathrm{CO} \rightarrow \mathrm{CO}_{2}} \\
{\left[\mathrm{kcal} \mathrm{mol}^{-1}\right]}\end{array}$ & $\begin{array}{l}\text { Pd-O bond } \\
\text { length }[\AA]\end{array}$ & Descriptor \\
\hline$+\mathrm{II}$ & $\mathrm{L}$ & $\mathrm{s}$ & -104.3 & 1.80 & $\Delta G_{\mathrm{s} / \mathrm{t}}$ \\
\hline$+\mathrm{II}$ & $\mathrm{L}_{3}$ & $\mathrm{~s}$ & -66.2 & 1.86 & $\left(\Delta G_{\mathrm{s} / \mathrm{t}}\right)^{a}$ \\
\hline$+\mathrm{IV}$ & $\mathrm{L}$ & t (o.s.s.) & -113.7 & 1.84 & $(\mathrm{TEP})^{b}$ \\
\hline$+\mathrm{IV}$ & $\mathrm{L}_{2}$ & $\mathrm{~s}(\mathrm{t}$, o.s.s. $)$ & -106.5 & 1.79 & TEP \\
\hline
\end{tabular}

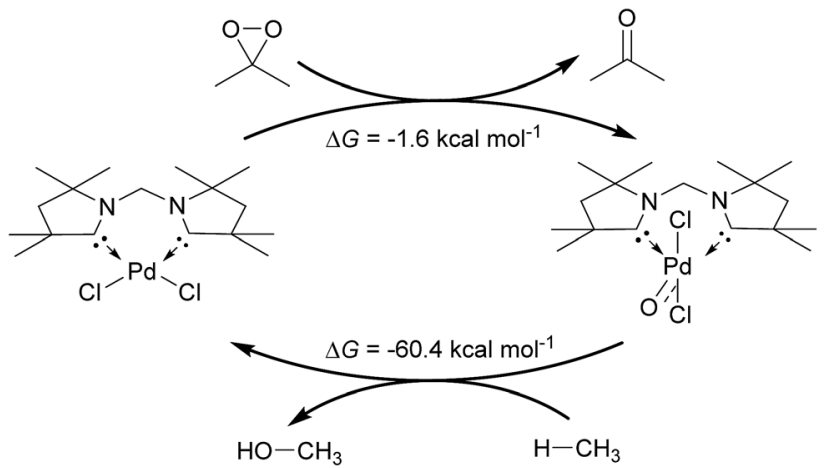

Fig. 13 Catalytic cycle for the oxidation of methane by DMDO and $24^{\mathrm{PdCl} 2}$

(transient) low-coordinate palladium(II) and high-valent palladium(Iv) terminal oxo complexes are best suited for the activation of strong bonds like e.g. $\mathrm{C}-\mathrm{H}$ bonds. However, whereas the ancillary ligands have a huge influence on the $\mathrm{O}$-atom transfer capabilities of the palladium(II) complexes, they allow only for a fine tuning for the palladium(Iv) compounds.

Inspired by the development of new catalytic processes for the activation of strong $\mathrm{O}-\mathrm{H}$ and $\mathrm{C}-\mathrm{H}$ bonds, we investigated briefly the thermodynamics for the catalytic oxidation of methane by the model complex $\mathbf{2 4}^{\mathbf{P d C l}_{2} \mathbf{O}}$ (Fig. 13). The formation of the terminal oxo complex $\mathbf{2 4}^{\mathbf{P d C l}_{2} \mathbf{O}}$ is predicted to be thermodynamically feasible through oxidation of the dichloride palladium(II) complex $\mathbf{2 4}^{\mathbf{P d C l} 2}$ by dimethyldioxirane (DMDO; $\Delta G$ $\left.=-1.6 \mathrm{kcal} \mathrm{mol}^{-1}\right)$. The oxyinsertion reaction with methane is very exergonic with $\Delta G=-60.4 \mathrm{kcal} \mathrm{mol}^{-1}$. We conclude therefore that $\mathrm{O}$-atom transfer reactivity should be comparably facile for all complexes investigated herein. The oxidation step to generate the palladium terminal oxo compound appears to be potentially more challenging.

\section{Conclusions}

Palladium terminal oxo complexes in the oxidation state of $+\mathrm{II}$ are predicted to show significant multiple bond character and closed-shell singlet ground states. Both the $\sigma$-donating and $\pi$ accepting properties as perfectly exemplified by ancillary cyclic (alkyl)(amino)carbene (CAAC) ligands in comparison to conventional NHC ligands are important for their thermodynamic stability. The singlet/triplet gap of the complexes, which can be controlled by the electronic properties of the ancillary ligand, is proposed to determine the reactivity of the terminal oxo group. Accordingly, potential redox activity of ancillary ligands has a remarkable influence on the electronic structure and stability.

Hydrogen bonds, which delocalize electron density from the terminal oxo ligand, enhance the stability of the basic terminal oxo complexes. Increasing the number of coordinating L-type ancillary ligands from one to three reduces the bond order, increases the dipolar character and reduces the reactivity of the Pd-O moiety. Overall, low-coordinate palladium(II) terminal oxo intermediates are therefore especially promising targets for the design of catalytic cycles for the activation of strong bonds.

The electronic structures of the complexes in the oxidation state of +IV are more diverse. Whereas for some cases the singlet state seems to be most stable (bidentate ligands), other ligand frameworks seem to rather favor the triplet configuration (monodentate ligands). Pd-O bonds with strong single-bond character are predicted. Most salient, the stability of the palladium(Iv) complexes is shown to be related to the overall donor properties of the ancillary ligands, although the influence is especially for the molecules with a triplet ground state small. The stability of these complexes can be quantified by the Tolman Electronic Parameter of the ancillary ligand. On the contrary to the palladium(II) complexes, the $\pi$-accepting properties of ancillary ligands are not very important. Consequently, strongly donating ligands are best suited for synthetic endeavors towards the isolation of high valent palladium(Iv) terminal oxo compounds. Accordingly, it also appears very plausible why Milstein's platinum(Iv) terminal oxo complex did not feature a ligand with considerable $\pi$-acceptor capabilities. Of particular interest, palladium(Iv) terminal oxos appear to be generally quite reactive and suitable candidates for the activation of very strong bonds.

In sight of those predictions, we believe that the synthetic isolation of palladium terminal oxo compounds is feasible with ancillary ligand systems providing balanced electronic stabilization and kinetic protection through a sterically encumbering ligand system. Consequently, we hope that such exciting compounds will become available for the scientific community in the future and will allow for the development of novel catalytic oxidation protocols. 


\section{Conflicts of interest}

There are no conflicts to declare.

\section{Acknowledgements}

Thanks are due to the German Academic Exchange Service DAAD for a postdoctoral fellowship and the Fonds der Chemischen Industrie im Verband der Chemischen Industrie e.V. for a Liebig fellowship. The W. M. Keck Foundation ("Keck2"; UC San Diego) and the Regionales Rechenzentrum Erlangen RRZE ("Woodcrest"; FAU Erlangen) are acknowledged for computational resources. Prof. K. Meyer and Prof. G. Bertrand are acknowledged for their generous support; PD Dr M. Khusniyarov and Prof. D. J. Mindiola are thanked for helpful discussions.

\section{Notes and references}

1 M. Shelef, Chem. Rev., 1995, 95, 209-225.

2 P. R. Sharp, J. Chem. Soc., Dalton Trans., 2000, 2647-2657.

3 J. Hohenberger, K. Ray and K. Meyer, Nat. Commun., 2012, 3, 720 .

4 B. Meunier, S. P. de Visser and S. Shaik, Chem. Rev., 2004, 104, 3947-3980.

5 B. Meunier and J. Bernadou, in Metal-Oxo and Metal-Peroxo Species in Catalytic Oxidations, ed. B. Meunier, Springer Berlin Heidelberg, Berlin, Heidelberg, 2000, pp. 1-35.

6 L. Que and W. B. Tolman, Nature, 2008, 455, 333-340.

7 S. A. Cook, D. C. Lacy and A. S. Borovik, in Spin States in Biochemistry and Inorganic Chemistry, John Wiley \& Sons, Ltd, 2015, pp. 203-227.

8 R. H. Holm, Chem. Rev., 1987, 87, 1401-1449.

9 M. Zhou and R. H. Crabtree, Chem. Soc. Rev., 2011, 40, 18751884.

10 A. Gunay and K. H. Theopold, Chem. Rev., 2010, 110, 10601081.

11 D. Balcells, E. Clot and O. Eisenstein, Chem. Rev., 2010, 110, 749-823.

12 P. Du and R. Eisenberg, Energy Environ. Sci., 2012, 5, 60126021.

13 S. Ye and F. Neese, Curr. Opin. Chem. Biol., 2009, 13, 89-98.

14 P. E. M. Siegbahn and R. H. Crabtree, in Metal-Oxo and Metal-Peroxo Species in Catalytic Oxidations, ed. B. Meunier, Springer Berlin Heidelberg, Berlin, Heidelberg, 2000, pp. 125-144.

15 For examples of the group 9, $\operatorname{see}(a)$ B. Wang, Y. M. Lee, W. Y. Tcho, S. Tussupbayev, S. T. Kim, Y. Kim, M. S. Seo, K. B. Cho, Y. Dede, B. C. Keegan, T. Ogura, S. H. Kim, T. Ohta, M. H. Baik, K. Ray, J. Shearer and W. Nam, Nat. Commun., 2017, 8, 14839; (b) R. S. Hay-Motherwell, G. Wilkinson, B. Hussain-Bates and M. B. Hursthouse, Polyhedron, 1993, 12, 2009-2012.

16 A. E. Shilov and G. B. Shulpin, Chem. Rev., 1997, 97, 28792932.

17 E. G. Chepaikin, Russ. Chem. Rev., 2011, 80, 363-396.
18 K. I. Goldberg and A. S. Goldman, Activation and Functionalization of $\mathrm{C}-\mathrm{H}$ Bonds, American Chemical Society, Washington, DC, 2004.

19 J. A. Labinger and J. E. Bercaw, Nature, 2002, 417, 507-514.

20 B. G. Hashiguchi, S. M. Bischof, M. M. Konnick and R. A. Periana, Acc. Chem. Res., 2012, 45, 885-898.

21 R. H. Crabtree, in Handbook of Green Chemistry - Green Catalysis: 1, ed. P. T. Anastas, Wiley-VCH, Weinheim, 2009.

22 Top. Organomet. Chem., Organometallic Oxidation Catalysis, ed. F. Meyer and C. Limberg, 2007, vol. 22, 2007.

23 H. Schwarz, Angew. Chem., Int. Ed., 2011, 50, 10096-10115.

24 A. N. Vedernikov, Acc. Chem. Res., 2012, 45, 803-813.

25 A. N. Campbell and S. S. Stahl, Acc. Chem. Res., 2012, 45, 851-863.

26 R. Wesendrup, D. Schröder and H. Schwarz, Angew. Chem., Int. Ed., 1994, 33, 1174-1176.

27 A. Božović, S. Feil, G. K. Koyanagi, A. A. Viggiano, X. Zhang, M. Schlangen, H. Schwarz and D. K. Bohme, Chem.-Eur. J., 2010, 16, 11605-11610.

28 J. Roithova and D. Schroder, Chem. Rev., 2010, 110, 11701211.

29 D. Schröder and H. Schwarz, Angew. Chem., Int. Ed., 1995, 107, 1973-1995.

30 D.-Y. Hwang and A. M. Mebel, J. Phys. Chem. A, 2002, 106, 12072-12083.

31 E. Broclawik, R. Yamauchi, A. Endou, M. Kubo and A. Miyamoto, Int. J. Quantum Chem., 1997, 61, 673-682.

32 E. Broclawik, R. Yamauchi, A. Endou, M. Kubo and A. Miyamoto, J. Chem. Phys., 1996, 104, 4098-4104.

33 P. L. Alsters, H. T. Teunissen, J. Boersma, A. L. Spek and G. v. Koten, Organometallics, 1993, 12, 4691-4696.

34 A. Behnia, P. D. Boyle, J. M. Blacquiere and R. J. Puddephatt, Organometallics, 2016, 35, 2645-2654.

35 K. Kamaraj and D. Bandyopadhyay, Organometallics, 1999, 18, 438-446.

36 P. Wadhwani and D. Bandyopadhyay, Organometallics, 2000, 19, 4435-4436.

37 J. E. Kukowski, K. J. Keuseman and I. P. Smoliakova, Transition Met. Chem., 2015, 40, 877-889.

38 F. F. Pfaff, F. Heims, S. Kundu, S. Mebs and K. Ray, Chem. Commun., 2012, 48, 3730-3732.

39 T. Corona, F. F. Pfaff, F. Acuña-Parés, A. Draksharapu, C. J. Whiteoak, V. Martin-Diaconescu, J. Lloret-Fillol, W. R. Browne, K. Ray and A. Company, Chem.-Eur. J., 2015, 21, 15029-15038.

40 T. Corona and A. Company, Chem.-Eur. J., 2016, 22, 1342213429.

41 S. Yao and M. Driess, Acc. Chem. Res., 2012, 45, 276-287.

42 M. Sankaralingam, M. Balamurugan, M. Palaniandavar, P. Vadivelu and C. H. Suresh, Chem.-Eur. J., 2014, 20, 11346-11361.

43 K. R. Pellarin, M. S. McCready and R. J. Puddephatt, Organometallics, 2012, 31, 6388-6394.

44 T. M. Figg, G. Schoendorff, B. Chilukuri and T. R. Cundari, Organometallics, 2013, 32, 4993-4996.

45 T. M. Figg, J. R. Webb, T. R. Cundari and T. B. Gunnoe, J. Am. Chem. Soc., 2012, 134, 2332-2339. 
46 T. M. Figg, T. R. Cundari and T. B. Gunnoe, Organometallics, 2011, 30, 3779-3785.

47 J. M. Mayer, Comments Inorg. Chem., 1988, 8, 125-135.

48 J. F. Berry, Comments Inorg. Chem., 2009, 30, 28-66.

49 J. R. Winkler and H. B. Gray, Struct. Bonding, 2012, 142, 1728.

50 C. J. Ballhausen and H. B. Gray, Inorg. Chem., 1962, 1, 111122.

51 T. A. Betley, Q. Wu, T. Van Voorhis and D. G. Nocera, Inorg. Chem., 2008, 47, 1849-1861.

52 K. Ray, F. Heims and F. F. Pfaff, Eur. J. Inorg. Chem., 2013, 2013, 3784-3807.

53 A. Singh, U. Anandhi, M. A. Cinellu and P. R. Sharp, Dalton Trans., 2008, 2314-2327.

54 K. P. O'Halloran, C. C. Zhao, N. S. Ando, A. J. Schultz, T. F. Koetzle, P. M. B. Piccoli, B. Hedman, K. O. Hodgson, E. Bobyr, M. L. Kirk, S. Knottenbelt, E. C. Depperman, B. Stein, T. M. Anderson, R. Cao, Y. V. Geletii, K. I. Hardcastle, D. G. Musaev, W. A. Neiwert, X. K. Fang, K. Morokuma, S. X. Wu, P. Kogerler and C. L. Hill, Inorg. Chem., 2012, 51, 7025-7031.

55 T. M. Anderson, W. A. Neiwert, M. L. Kirk, P. M. B. Piccoli, A. J. Schultz, T. F. Koetzle, D. G. Musaev, K. Morokuma, R. Cao and C. L. Hill, Science, 2012, 337, 290.

56 E. Poverenov, I. Efremenko, A. I. Frenkel, Y. Ben-David, L. J. W. Shimon, G. Leitus, L. Konstantinovski, J. M. L. Martin and D. Milstein, Nature, 2008, 455, 10931096.

57 C. Limberg, Angew. Chem., Int. Ed., 2009, 48, 2270-2273.

58 E. Spaltenstein, R. R. Conry, S. C. Critchlow and J. M. Mayer, J. Am. Chem. Soc., 1989, 111, 8741-8742.

59 I. Efremenko, E. Poverenov, J. M. L. Martin and D. Milstein, J. Am. Chem. Soc., 2010, 132, 14886-14900.

60 J. P. Wagner and P. R. Schreiner, Angew. Chem., Int. Ed., 2015, 54, 12274-12296.

61 J. P. Wagner and P. R. Schreiner, J. Chem. Theory Comput., 2016, 12, 231-237.

62 R. Okazaki, Heteroat. Chem., 2014, 25, 293-305.

63 K. J. Bonney and F. Schoenebeck, Chem. Soc. Rev., 2014, 43, 6609-6638.

64 M. J. Frisch, et al., Gaussian 09, Rev. D01, Gaussian Inc.: Wallingford CT, 2009.

65 A. D. Becke, J. Chem. Phys., 1993, 98, 5648-5652.

66 C. Lee, W. Yang and R. G. Parr, Phys. Rev. B: Condens. Matter, 1988, 37, 785-789.

67 P. J. Stephens, F. J. Devlin, C. F. Chabalowski and M. J. Frisch, J. Phys. Chem., 1994, 98, 11623-11627.

68 S. H. Vosko, L. Wilk and M. Nusair, Can. J. Phys., 1980, 58, 1200-1211.

69 F. Weigend and R. Ahlrichs, Phys. Chem. Chem. Phys., 2005, 7, 3297-3305.

70 D. Andrae, U. Häußermann, M. Dolg, H. Stoll and H. Preuß, Theor. Chim. Acta, 1990, 77, 123-141.

71 S. Grimme, J. Antony, S. Ehrlich and H. Krieg, J. Chem. Phys., 2010, 132, 154104.

72 S. Grimme, S. Ehrlich and L. Goerigk, J. Comput. Chem., 2011, 32, 1456-1465.
73 A. Klamt and G. Schueuermann, J. Chem. Soc., Perkin Trans. 2, 1993, 799-805.

74 C. Angeli, R. Cimiraglia, S. Evangelisti, T. Leininger and J. P. Malrieu, J. Chem. Phys., 2001, 114, 10252-10264.

75 N. Ferre, N. Guihery and J. P. Malrieu, Phys. Chem. Chem. Phys., 2015, 17, 14375-14382.

76 S. Yamanaka, T. Kawakami, H. Nagao and K. Yamaguchi, Chem. Phys. Lett., 1994, 231, 25-33.

77 J. P. Malrieu and G. Trinquier, J. Phys. Chem. A, 2012, 116, 8226-8237.

78 F. Neese, J. Phys. Chem. Solids, 2004, 65, 781-785.

79 E. D. Glendening, C. R. Landis and F. Weinhold, J. Comput. Chem., 2013, 34, 1429-1437.

80 S. I. Gorelsky, AOMix: Program for Molecular Orbital Analysis, version $6.88,2016$, http://www.sg-chem.net.

81 S. I. Gorelsky and A. B. P. Lever, J. Organomet. Chem., 2001, 635, 187-196.

82 D. G. Gusev, Organometallics, 2009, 28, 6458-6461.

83 D. G. Gusev, Organometallics, 2009, 28, 763-770.

84 G. Knizia and J. E. M. N. Klein, Angew. Chem., Int. Ed., 2015, 54, 5518-5522.

85 G. Schaftenaar and J. H. Noordik, J. Comput.-Aided Mol. Des., 2000, 14, 123-134.

86 M. D. Hanwell, D. E. Curtis, D. C. Lonie, T. Vandermeersch, E. Zurek and G. R. Hutchison, J. Cheminf., 2012, 4, 1-17.

87 M. C. Lehman, D. R. Pahls, J. M. Meredith, R. D. Sommer, D. M. Heinekey, T. R. Cundari and E. A. Ison, J. Am. Chem. Soc., 2015, 137, 3574-3584.

88 Exploratory calculations with larger active spaces with the inclusion of further d-orbitals suggest as well a singlet ground state.

89 M. Reiher, Inorg. Chem., 2002, 41, 6928-6935.

90 C. Riplinger and F. Neese, J. Chem. Phys., 2013, 138, 034106.

91 For examples with terminal manganese oxo compound, see

(a) R. Gupta, T. Taguchi, B. Lassalle-Kaiser, E. L. Bominaar, J. Yano, M. P. Hendrich and A. S. Borovik, Proc. Natl. Acad. Sci. U. S. A., 2015, 112, 5319-5324; (b) D. C. Ashley and M. Baik, ACS Catal., 2016, 6, 7202-7209; (c) B. LassalleKaiser, C. Hureau, D. A. Pantazis, Y. Pushkar, R. Guillot, V. K. Yachandra, J. Yano, F. Neese and E. AnxolabehereMallart, Energy Environ. Sci., 2010, 3, 924-938; for an example involving a copper oxyl intermediate, see ; S. M. Huber, M. Z. Ertem, F. Aquilante, L. Gagliardi, W. B. Tolman and C. J. Cramer, Chem.-Eur. J., 2009, 15, 4886-4895. ; for examples regarding redox-active ligands, see $(d)$ N. Muresan, C. C. Lu, M. Ghosh, J. C. Peters, M. Abe, L. M. Henling, T. Weyhermüller, E. Bill and K. Wieghardt, Inorg. Chem., 2008, 47, 4579-4590; (e) V. Bachler, G. Olbrich, F. Neese and K. Wieghardt, Inorg. Chem., 2001, 41, 4179-4193; for application of the broken symmetry formalism with redox active CAAC ligands, see ; (f) K. C. Mondal, B. Dittrich, B. Maity, D. Koley and H. W. Roesky, J. Am. Chem. Soc., 2014, 136, 9568-9571; $(g)$ A. P. Singh, P. P. Samuel, H. W. Roesky, M. C. Schwarzer, G. Frenking, N. S. Sidhu and B. Dittrich, J. Am. Chem. Soc., 2013, 135, 7324-7329. 
92 J. Grafenstein, E. Kraka, M. Filatov and D. Cremer, Int. J. Mol. Sci., 2002, 3, 360-394.

93 D. J. Mindiola, R. Waterman, V. M. Iluc, T. R. Cundari and G. L. Hillhouse, Inorg. Chem., 2014, 53, 13227-13238.

94 D. J. Mindiola and G. L. Hillhouse, J. Am. Chem. Soc., 2001, 123, 4623-4624.

95 N. D. Harrold and G. L. Hillhouse, Chem. Sci., 2013, 4, 40114015.

96 R. Waterman and G. L. Hillhouse, J. Am. Chem. Soc., 2003, 125, 13350-13351.

97 F. E. Hahn and M. C. Jahnke, Angew. Chem., Int. Ed., 2008, 47, 3122-3172.

98 M. Melaimi, M. Soleilhavoup and G. Bertrand, Angew. Chem., Int. Ed., 2010, 49, 8810-8849.

99 S. P. E. Nolan, N-Heterocyclic Carbenes in Synthesis, WileyVCH, New-York, 2006.

100 R. H. Crabtree, Coord. Chem. Rev., 2013, 257, 755-766.

101 O. Schuster, L. R. Yang, H. G. Raubenheimer and M. Albrecht, Chem. Rev., 2009, 109, 3445-3478.

102 T. W. H. a. C. W. Bielawski, J. Am. Chem. Soc., 2009, 131, 16039-16041.

103 M. Soleilhavoup and G. Bertrand, Acc. Chem. Res., 2015, 48, 256-266.

104 S. Roy, K. C. Mondal and H. W. Roesky, Acc. Chem. Res., 2016, 49, 357-369.

105 D. J. Nelson and S. P. Nolan, Chem. Soc. Rev., 2013, 42, 6723-6753.

106 T. Droge and F. Glorius, Angew. Chem., Int. Ed., 2010, 49, 6940-6952.

107 K. C. Mondal, S. Roy, B. Maity, D. Koley and H. W. Roesky, Inorg. Chem., 2016, 55, 163-169.

108 O. Back, M. Henry-Ellinger, C. D. Martin, D. Martin and G. Bertrand, Angew. Chem., Int. Ed., 2013, 52, 2939-2943.

109 A. Liske, K. Verlinden, H. Buhl, K. Schaper and C. Ganter, Organometallics, 2013, 32, 5269-5272.

110 S. V. C. Vummaleti, D. J. Nelson, A. Poater, A. GomezSuarez, D. B. Cordes, A. M. Z. Slawin, S. P. Nolan and L. Cavallo, Chem. Sci., 2015, 6, 1895-1904.

111 D. M. Andrada, N. Holzmann, T. Hamadi and G. Frenking, Beilstein J. Org. Chem., 2015, 11, 2727-2736.

112 D. Nemcsok, K. Wichmann and G. Frenking, Organometallics, 2004, 23, 3640-3646.

113 R. Tonner, G. Heydenrych and G. Frenking, Chem.-Asian J., 2007, 2, 1555-1567.

114 H. Jacobsen, A. Correa, A. Poater, C. Costabile and L. Cavallo, Coord. Chem. Rev., 2009, 253, 687-703.

115 H. Jacobsen, A. Correa, C. Costabile and L. Cavallo, J. Organomet. Chem., 2006, 691, 4350-4358.

116 T. Strassner, Top. Organomet. Chem., in Metal Carbenes in Organic Synthesis, ed. K. H. Dötz, 2004, vol. 13.

117 H. V. Huynh and G. Frison, J. Org. Chem., 2013, 78, 328-338.

118 T. M. Baker, T. L. Mako, A. Vasilopoulos, B. Li, J. A. Byers and M. L. Neidig, Organometallics, 2016, 35, 3692-3700.

119 K. L. Fillman, J. A. Przyojski, M. H. Al-Afyouni, Z. J. Tonzetich and M. L. Neidig, Chem. Sci., 2015, 6, 1178-1188.
120 S. J. K. Jensen, T.-H. Tang and I. G. Csizmadia, J. Phys. Chem. A, 2003, 8975-8979.

121 S. J. Grabowski, Chem. Rev., 2011, 111, 2597-2625.

122 C. E. MacBeth, R. Gupta, K. R. Mitchell-Koch, V. G. Young, G. H. Lushington, W. H. Thompson, M. P. Hendrich and A. S. Borovik, J. Am. Chem. Soc., 2004, 126, 2556-2567.

123 E. D. Glendening and F. Weinhold, J. Comput. Chem., 1998, 19, 593-609.

124 K. Kitaura and K. Morokuma, Int. J. Quantum Chem., 1976, 10, 325-340.

125 T. Ziegler and A. Rauk, Theor. Chim. Acta, 1977, 46, 1-10.

126 M. v. Hopffgarten and G. Frenking, Wiley Interdiscip. Rev.: Comput. Mol. Sci., 2012, 2, 43-62.

127 The basis set superposition error (BSSE) was estimated via counterpoise calculation to be $+4.1 \mathrm{kcal} \mathrm{mol}^{-1}$, whereas the D3 dispersion correction leads to a stabilization of $-3.0 \mathrm{kcal} \mathrm{mol}^{-1}$.

128 P. Comba, S. Fukuzumi, C. Koke, B. Martin, A.-M. Löhr and J. Straub, Angew. Chem., Int. Ed., 2016, 55, 11129-11133.

129 A. Kazaryan and E. J. Baerends, ACS Catal., 2015, 5, 14751488.

130 S. Ye, C.-Y. Geng, S. Shaik and F. Neese, Phys. Chem. Chem. Phys., 2013, 15, 8017-8030.

131 D. H. Ess, T. B. Gunnoe, T. R. Cundari, W. A. Goddard and R. A. Periana, Organometallics, 2010, 29, 6801-6815.

132 D. Devarajan, T. B. Gunnoe and D. H. Ess, Inorg. Chem., 2012, 51, 6710-6718.

133 N. Dietl, M. Schlangen and H. Schwarz, Angew. Chem., Int. Ed., 2012, 51, 5544-5555.

134 L. Q. Deng and T. Ziegler, Organometallics, 1996, 15, 30113021.

135 D. N. Bowman, A. Bondarev, S. Mukherjee and E. Jakubikova, Inorg. Chem., 2015, 54, 8786-8793.

136 T. Birk and J. Bendix, Inorg. Chem., 2003, 42, 7608-7615.

137 J. Bendix, J. Am. Chem. Soc., 2003, 125, 13348-13349.

138 J. Chu, D. Munz, R. Jazzar, M. Melaimi and G. Bertrand, J. Am. Chem. Soc., 2016, 138, 7884-7887.

139 J. A. Mata, M. Poyatos and E. Peris, Coord. Chem. Rev., 2007, 251, 841-859.

$14016^{\mathbf{P d O}}$ and $22^{\mathbf{P d O}}$ are omitted due to instability towards the formation of phosphine oxide $\left(\mathbf{1 6}^{\mathbf{P d O}}\right)$ or instability of the carbonyl $\mathrm{Pd}^{0}$ complex $\left(\mathbf{2 2}{ }^{\mathbf{P d O}}\right)$.

141 TEP values were obtained from ref. 82 (NHC, sa-NHC, benzNHC) or calculated accordingly (MIC, CAAC, DAC). For further details see the ESI. $\dagger$

142 M. Poyatos, J. A. Mata and E. Peris, Chem. Rev., 2009, 109, 3677-3707.

143 S. C. Bart, K. Chłopek, E. Bill, M. W. Bouwkamp, E. Lobkovsky, F. Neese, K. Wieghardt and P. J. Chirik, J. Am. Chem. Soc., 2006, 128, 13901-13912.

144 V. Lyaskovskyy and B. de Bruin, ACS Catal., 2012, 2, 270279.

145 L. A. Berben, B. de Bruin and A. F. Heyduk, Chem. Commun., 2015, 51, 1553-1554. 